\title{
Association between Aspergillus flavus Colonization and Aflatoxins Production in Immature Grains of Maize Genotypes
}

\author{
María Carolina de Luna-López ${ }^{1}$, Arturo Gerardo Valdivia-Flores ${ }^{1}$, Fernando Jaramillo-Juárez ${ }^{2}$, José Luis Reyes ${ }^{3}$, \\ Raúl Ortiz-Martínez ${ }^{1}$ and Teódulo Quezada-Tristán ${ }^{1}$ \\ 1. Agricultural Sciences Centre, Mycotoxicology, Aguascalientes Autonomous University, Aguascalientes 20131, Mexico \\ 2. Basic Sciences Centre, Toxicology, Aguascalientes Autonomous University, Aguascalientes 20131, México \\ 3. Department of Physiology and Biophysics, Toxicology, Center for Research and Advanced Studies-I. P. N., México, D. F. 07360, \\ Mexico
}

Received: September 22, 2013 / Published: December 20, 2013.

\begin{abstract}
Aspergillus flavus maize colonization leads to crop contamination by toxic secondary metabolites and carcinogens called aflatoxins (AF); it has negative effects in public health and has caused economic losses in agricultural activities. Eleven genotypes of immature maize grain frequently used in Mexico were inoculated in vitro with two indigenous toxigenic strains of $A$. flavus. The size of inoculum, temperature, humidity and presence of other phytopathogens were assessed. Genotypes Popcorn, C-526, Garst 8366, As 910 and 30G40 showed resistance to rating of fungal colonization (FC) and AF accumulation, while 3002W, 30R39, Creole, C-922, HV313 and $P 3028 \mathrm{~W}$ genotypes were less resistant. $\mathrm{AFB}_{1}$ had the highest concentrations $(26.1 \mathrm{mg} / \mathrm{kg} \pm 14.7 \mathrm{mg} / \mathrm{kg})$, while $\mathrm{AFB}_{2}, \mathrm{AFG}_{1}$ and $\mathrm{AFG}_{2}$ showed only residual concentrations $1.6,2.0$ and $4.0 \mu \mathrm{g} / \mathrm{kg}$, respectively. Concerning $\mathrm{FC}$ and $\mathrm{AF}$, there were significant differences $(P<0.01)$ between strains and genotype. Both strains showed significant association $(P<0.01)$ between FC and the concentrations of $\mathrm{AFB}_{1}$ and $\mathrm{AFB}_{2}\left(R^{2}: 99.5 \%\right.$ and $93.2 \% ; 87.2 \%$ and $73.2 \%$, respectively). Results suggest that the level of resistance to fungus infection and AF accumulation is related to maize genotype. It emphasizes the relevance of developing $A$. flavus resistant maize genotypes as an alternative to control contamination in foodstuff intended for human and animal consumption.
\end{abstract}

Key words: AF, Aspergillus flavus, immature maize grain, resistance, Mexico.

\section{Introduction}

Aflatoxins (AF) are secondary toxic metabolites produced by several fungi, mainly the Aspergillus spp. which grows on grains and seeds, changing their texture, flavour, color and quality. Presence of AF in cereals is related mainly to A. flavus infection during plant development [1, 2]. Improper handling of humidity and temperature in agricultural products are factors that favor infection with A. flavus [3-5].

Globally, maize (Zea mays L.) provides $15 \%$ of the

Corresponding author: Arturo Gerardo Valdivia-Flores, Ph.D., researcher, research field: mycotoxins. E-mail: avaldiv@correo.uaa.mx. proteins and $20 \%$ of the calories in diets. Furthermore, in developing countries such as Latin America, Africa and Asia, maize is a staple food and occasionally is the only protein source in their diets [6]. Around 78\% of maize samples are contaminated with AF [7]. Economic losses attributed to $\mathrm{AF}$ contamination are large $[8,9]$, mainly in developing countries that lack the appropriate regulations for the control of mycotoxin contaminated foods [10]. In Mexico, the presence of maize contaminated with A. flavus strains has also been documented [4, 11-15]. This is relevant due to the high national consumption of maize (20 million $\mathrm{t} /$ year) as well as per capita (329 $\mathrm{g}$ daily). In addition, the use of maize in animal feed is increasing, 
leading to an increase in its production in recent years $[4,13,16]$.

$\mathrm{AF}$ is extremely toxic compounds that have carcinogenic, mutagenic, teratogenic and immunosuppressive capacities [17]. Therefore AF contamination in agricultural products is a serious public health problem, and affects productivity in domestic animals and agriculture in general [18]. For these reasons, many countries have established maximum permitted levels of AF concentration in food destined for human and animal consumption. For instance, the U.S. Food and Drug Administration established a limit of $20 \mathrm{ppb}$ of AF in cereals and 0.05 ppb $\mathrm{AFM}_{1}$ in milk [14].

Because mycotoxins are unavoidable in worldwide, they have become one of the leading perils in both the feed and food industry. Strategies have been developed in order to control the presence of $\mathrm{AF}$ in maize, either by eliminating or reducing them to acceptable levels. For AF reduction, it is recommended: (1) to improve agricultural practices and storage conditions [19], (2) insect control [20-22], and (3) the use of natural or synthetic products to prevent toxicogenic fungi growth [14]. However these strategies have been proved to be insufficient, as approximately $25 \%$ of the agricultural production destined for consumption is contaminated with mycotoxins [23]. Therefore, concern for the use of mycotoxin-contaminated matrices dictates increased understanding about the plant and fungus interactions and presence of host-plant resistance to mycotoxin-producing fungi and mycotoxins occurrence [8].

An alternative for food contamination control is the use of maize and other cereal genotypes with genetic characteristics that provide them resistance to prevent development of phytopathogenic and toxic fungi. This seems to be a safe and economically adequate option to reduce the AF maize accumulation [24]. Maize infection with $A$. flavus and AF accumulation depends on the innate susceptibility of grain and the environmental factors which contribute to it, as well as the ability of the fungus to penetrate the grain [25]. Studies on breeding to improve resistance of maize strains have reported the importance of several factors involved in the infection process of grains with $A$. flavus: (1) presence of antifungal proteins [26], (2) regulatory factors in signal transduction [27], and (3) physical barriers [28].

Restricted development of $A$. flavus has been reported in some maize genotypes [9, 29]. Many breeding programs to evaluate the resistance to $\mathrm{AF}$ contamination in several maize genotypes use commercial strains of A. flavus which are characterized by a high production of $\mathrm{AF}[19,30-33]$. It is known that in field infections, A. flavus strains show variable ability to contaminate agricultural products [9]; in addition, there is little information on the capacity of commercial maize phenotypes to resist damage caused by field strains. Indigenous strains of $A$. flavus which are called Cuahutitlán and Tamaulipas, have demonstrated the ability to infect local cornfields and caused aflatoxin contamination of cereal crops $[3,4,13]$ as well as the ability to damage the physiological functioning and histological structure in animals [34]. In Mexico and the State of Aguascalientes, the use of hybrid maize has increased in recent decades. However, forage maize hybrids used have been developed to improve grain yield [35], neglecting the quality of the forage [36] as well as its resistance to diseases.

The aim of this study was to evaluate the resistance of 11 maize genotypes to $\mathrm{AF}$ accumulation, AFs produced by two Mexican strains of Aspergillus flavus under controlled conditions of temperature, humidity and infective dose.

\section{Materials and Methods}

\subsection{Grain Preparation}

Immature maize grains of 11 genotypes (Creole, 30R39, P3028W, HV313, Popcorn, C-526, 3002W, C-922, Garst 8366, As910, 30G40; Fig. 1) conventionally grown in the State of Aguascalientes were used, and their main characteristics are shown in 
Table 1. These genotypes were donated by the Forage Production Unit of the Aguascalientes Autonomous University in Mexico.

The maize was harvested 100 days after seeding. They were placed in paper bags for dehydration in an oven $\left(55^{\circ} \mathrm{C} / 13\right.$ days), and the initial humidity content was calculated for each genotype. Grains were collected from dehydrated cobs and kept in hermetic containers. Before fungal inoculation, grains were allocated in glass containers with lids ( $400 \mathrm{~g} /$ container) and sterilized $\left(121{ }^{\circ} \mathrm{C}, 15 \mathrm{~min}\right)$. To verify the absence of other contaminant flora, 500 seeds of each genotype were sown in MSA media (malt $2 \%$, salt $6 \%$ and agar $2 \%$ ) for eight days at $25^{\circ} \mathrm{C}$ [37].

\subsection{Grain Inoculation with A. flavus Spores}

Cuautitlán and Tamaulipas strains of A. flavus considered as toxigenic ${ }^{1}$ were used. Strains were cultured in Petri dishes with potato-dextrose agar and incubated at $27{ }^{\circ} \mathrm{C}$ for 10 days. To obtain spores, Petri dishes were washed with Tween 20 at $0.1 \%$. Spore concentration was calculated using a hemocytometer to obtain a stock solution $\left(5 \times 10^{6}\right.$ spores $\left./ \mathrm{mL}\right)$ to inoculate. Paraffin oil (1\%) was added as fixer to the spore suspension [38]. Recommended security procedures for handling A. flavus cultures were followed [39]. Laboratory equipment was submerged for $5 \mathrm{~min}$ in a sodium hypochlorite solution $(1: 10, \mathrm{v} / \mathrm{v})$, and working areas were sanitized with $6 \%$ sodium hypochlorite [40]. Maize grains were inoculated using a sterile non-invasive technique with $5 \mathrm{~mL}$ of inoculum $(2.5 \times$ $10^{5}$ spores/g grain), and the humidity was adjusted to $15 \%$ by adding sterile distilled water. Flasks were agitated daily to prevent adhesion.

Three treatments were designed for each of the 11 maize genotypes ( $n=20$ flasks): (1) control group; (2) Cuautitlán strain; (3) Tamaulipas strain. The control group was not inoculated, but it was handled as groups 2 and 3 (humidity, spore fixer, temperature and period

\footnotetext{
${ }^{1}$ Mycotoxin Laboratory, Biology Institute, Universidad Nacional Autónoma de México.
}

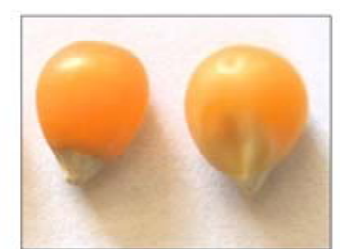

(a)

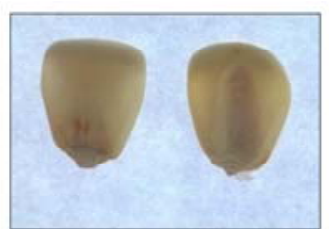

(c)

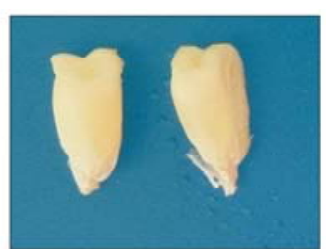

(b)

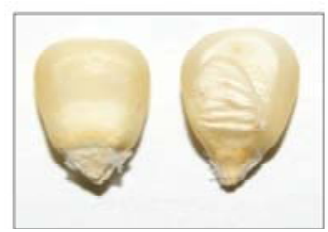

(d)

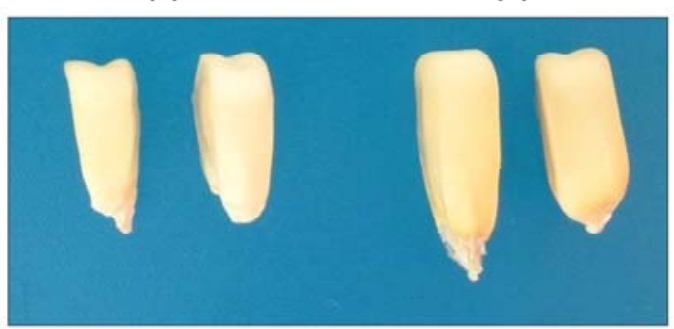

(e)

Fig. 1 Morphological characteristics of maize genotypes used. (a): yellow and non-jagged grains (Popcorn); (b): white, opaque and jagged gains (Creole, P3028W); (c): (translucid view) and (d): white, opaque and non-jagged grains ( $H V 313$, C526); (e): white, semi-crystalline and semi-jagged grains (As910, 30R39, 3002W, Gartz 8366, $30 G 40$ and C-922).

of assay). Each flask represents one experimental unit. Flasks were incubated at $27{ }^{\circ} \mathrm{C} \pm 2{ }^{\circ} \mathrm{C}$. The growth of Aspergillus flavus was recorded after 14 days of incubation. Fungal colonization (FC) level was expressed as the percentage of invasion on the surface of the grains, assigning levels $0,1,2$ or $3(0 \%, 1 \%-33 \%$, $34 \%-67 \%, 68 \%-100 \%$, respectively), according to the modified method of Guo et al. [41].

\subsection{AF Quantification}

Inoculated maize genotypes and controls were processed in a mill, inoculated and sieved $(850 \mu \mathrm{m}$ mesh). Flour was kept in hermetically sealed bags and maintained frozen at $-20{ }^{\circ} \mathrm{C}$ until analyzed. To quantify $\mathrm{AF}$ concentrations $\left(\mathrm{AFB}_{1}, \mathrm{AFB}_{2}, \mathrm{AFG}_{1}\right.$ and $\left.\mathrm{AFG}_{2}\right)$, samples were analyzed according to the Association of Official Analytical Chemists (AOAC) official methods [42]. Extraction tubes were used during the solid phase (Supelclean LC-CN, Supelco Inc., Bellefonte, PA). 
Table 1 Genotypes of immature maize grains used for inoculation with spores of Aspergillus flavus.

\begin{tabular}{|c|c|c|c|}
\hline Genotypes & Source & Features & Initial moisture ( $\%$, average $)$ \\
\hline Creole & Local & $\begin{array}{l}\text { Natural cross } \\
\text { White jagged grains } \\
\text { Low resistance to pests }\end{array}$ & 10.2 \\
\hline $30 R 39$ & Pioneer & High grain yield & 13.5 \\
\hline P3028W & Pioneer & $\begin{array}{l}\text { Modified single cross } \\
\text { White jagged grains } \\
\text { Low resistance to pests } \\
\text { Tolerant to lodging and foliar diseases }\end{array}$ & 14.4 \\
\hline$H V 313$ & Caloro & $\begin{array}{l}\text { Varietal cross } \\
\text { White semi-crystalline grains } \\
\text { High grain yield }\end{array}$ & 13.2 \\
\hline Popcorn & Local & $\begin{array}{l}\text { Natural cross } \\
\text { Smooth small yellow hard grains } \\
\text { Low resistance to diseases }\end{array}$ & 18.0 \\
\hline$C-526$ & Hartz seed & $\begin{array}{l}\text { White semi-crystalline grains } \\
\text { High grain yield } \\
\text { Tolerant to H. turcicum, rust, Fusarium (stem), head smut }\end{array}$ & 19.0 \\
\hline $3002 \mathrm{~W}$ & Pioneer & $\begin{array}{l}\text { High forage yield } \\
\text { Tolerant to diseases }\end{array}$ & 11.0 \\
\hline$C-922$ & Hartz seed & $\begin{array}{l}\text { Semi-crystalline grains } \\
\text { High grain yield } \\
\text { Tolerant to diseases }\end{array}$ & 18.7 \\
\hline Garst 8366 & Garst & $\begin{array}{l}\text { Modified single cross } \\
\text { White semi-crystalline grains } \\
\text { High grain yield }\end{array}$ & 12.8 \\
\hline As910 & Aspros & $\begin{array}{l}\text { Triple cross } \\
\text { White semi-jagged grains } \\
\text { High grain yield } \\
\text { Tolerant to lodging and foliar diseases }\end{array}$ & 13.4 \\
\hline $30 G 40$ & Pioneer & $\begin{array}{l}\text { Modified single cross } \\
\text { White semi-crystalline grains } \\
\text { High grain yield } \\
\text { Tolerant to lodging and foliar diseases } \\
\end{array}$ & 16.4 \\
\hline
\end{tabular}

Extracted eluate was derived and analyzed by a HPLC system with fluorescence detector (Varian ProStar binary pump; FP 2020 detector, Varian Associates Inc., Victoria, Australia; SupelcosilHPLC LC-18 Column, Supelco Inc.). AF concentrations were calculated by a standard curve from purified AF $\left(B_{1}, B_{2}, G_{1}, G_{2} ;\right.$ Sigma $)$ obtained by using the same methodology.

In order to perform $\mathrm{AF}$ extraction, $50 \mathrm{~g}$ of each corn samples were mixed with methanol:water $(8: 2, \mathrm{v} / \mathrm{v})$, then they were eluted in solid-phase cartridges (SPE) using acetic acid $0.5 \%$. SPE were washed with tetrahydrofuran $20 \%$ (THF), then hexane and finally THF 25\%. Eluate was obtained with methylene chloride:THF $20 \%$ (99:1), it was evaporated to full dryness under nitrogen stream. To achieve an adequate identification and quantitation of $\mathrm{AFB}_{1}$, samples were derivatized to $\mathrm{AFB}_{1}$ hemiacetal $\left(\mathrm{AFB}_{2 \mathrm{a}}\right)$, a fluorescent compound, using trifluoroacetic acid. The $\mathrm{AFB}_{2 \mathrm{a}}$ was injected to HPLC system under following conditions: C18 column (SupelcosilHPLC LC-18 Column, 150 $\mathrm{mm} \times 4.6 \mathrm{~mm}$, Supelco Inc.); temperature $\left(25^{\circ} \mathrm{C} \pm\right.$ $\left.2{ }^{\circ} \mathrm{C}\right)$; mobile phase acetonitrile:methanol:water $(1: 1: 2$,

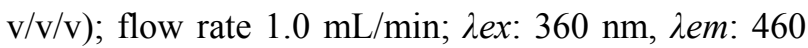
nm (Varian ProStar binary pump; FP 2020 detector, Varian Associates Inc., Victoria, Australia); injection volume $20 \mu \mathrm{L}$. Quantitation of $\mathrm{AF}$ was performed using a standard curve of purified $\mathrm{AF}\left(\mathrm{B}_{1}, \mathrm{~B}_{2}, \mathrm{G}_{1}, \mathrm{G}_{2}\right.$; Sigma Aldrich; Fig. 2b) according to the AOAC [42]. The $\mathrm{AFB}_{1}$ production by both strains of de A. flavus was determined in every established times in potato dextrose agar (PDA) media culture. Minimum detection limit was $0.3 \mathrm{ng} / \mathrm{g}$ for each $\mathrm{AF}$. The quantitation 

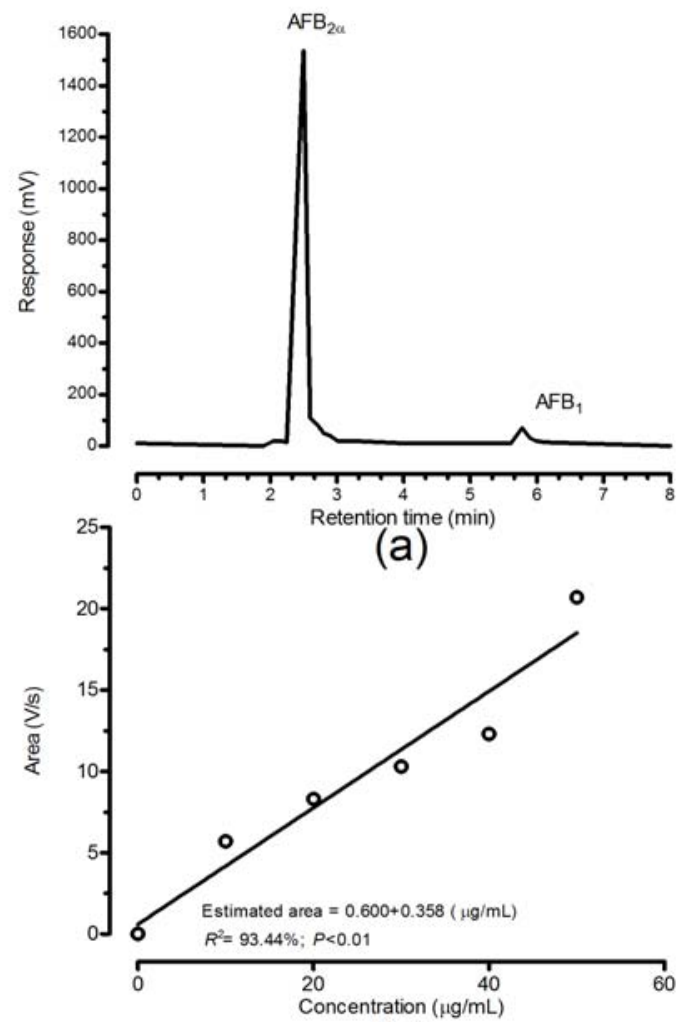

(b)

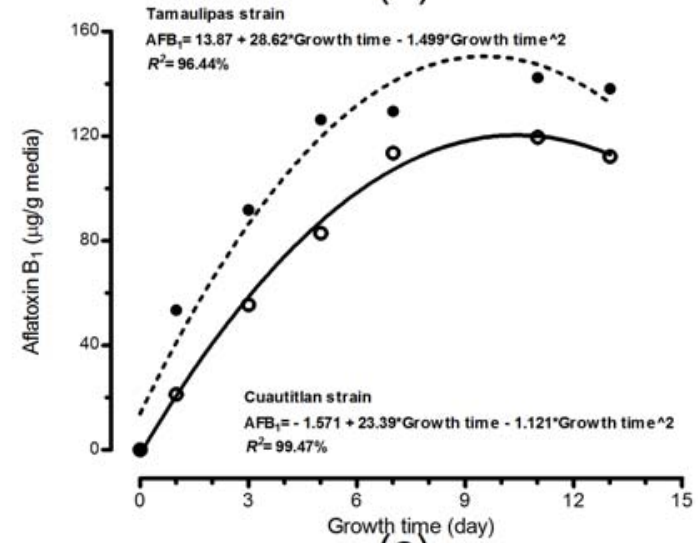

(c)

Fig. 2 Analysis and production of $\mathrm{AFB}_{1}$. (a): chromatogram of derivatized $\mathrm{AFB}_{1}\left(\mathrm{AFB}_{2 \mathrm{a}}\right)$; (b): linear regression analysis of the standard curve; (c): the second-order polynomial equation describes the $\mathrm{AFB}_{1}$ production by Cuautitlan and Tamaulipas strains of Aspergillus flavus, points represent actual data of $\mathbf{A F B}_{1}$.

data were obtained via Galaxie (Ver. 1.9.302.530) software.

\subsection{Statistical Analysis}

Colonization and AF production rates were analyzed by one way analysis of variance (ANOVA). To determine the association between fungal colonization rate and $\mathrm{AF}$ production, lineal regression analyzes were performed. To correlate these two variables, a Pearson correlation analysis was carried out. AF production curves were adjusted for second-order polynomial regression (Fig. 2c). $P<0.05$ was considered as significant. SAS V8 software was used (SAS Institute, Cary, NC, USA).

\section{Results and Discussion}

This study evaluated the resistance of 11 maize grain genotypes to $\mathrm{FC}$, as well as AF accumulation from two toxicogenic A. flavus strains during 14 days. There were significant differences in AF accumulation, which was related with $\mathrm{FC}$ on the different maize genotypes. Popcorn, Garst 8366, As910, C-526 and $30 G 40$ showed the highest resistance to infection by the Cuautitlan strain (Fig. 3a). For the Tamaulipas strain (Fig. 3b), maize genotypes As910, Garst 8366 and $30 G 40$ showed resistance to fungal infection. Resistant genotypes evidenced significantly lower FC $(P<0.01$, level $1=$ slow and scarce $)$, compared to their respective controls. The Popcorn and C-526 genotypes were resistant to the Cuautitlan strain but not to the Tamaulipas strain. This difference indicates that the Tamaulipas strain is more aggressive than the Cuautitlan strain. The control group did not show apparent FC (0 level) with any of the $A$. flavus strains.

Those maize genotypes that were susceptible to fungal infection showed a rapid and abundant FC (level 3 ), compared to their corresponding controls.

$\mathrm{AFB}_{1}$ showed the highest concentration $(26.1 \mathrm{mg} / \mathrm{kg}$ $\pm 14.7 \mathrm{mg} / \mathrm{kg}$ ), while types of $\mathrm{B}_{2}, \mathrm{G}_{1}$ and $\mathrm{G}_{2}$ showed only residual concentrations $(1.6,2.0$ and $4.0 \mu \mathrm{g} / \mathrm{kg}$, respectively) in all studied genotypes and both strains.

Maize genotypes which showed resistance to infection by the Cuautitlan fungal strain, also showed lower accumulation of $\mathrm{AFB}_{1}$ (C-526, Popcorn, 30G40, As 910 and Garst 8366; Fig. 3c). In addition, genotypes resistant to infection by the Tamaulipas strain were also resistant to $\mathrm{AFB}_{1}$ accumulation (As910, Garst 8366 
Cuautitlan strain

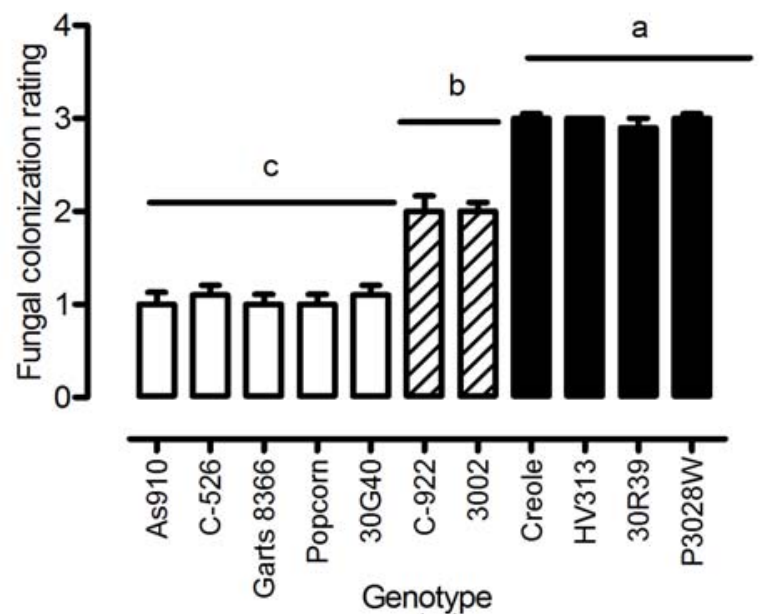

(a)
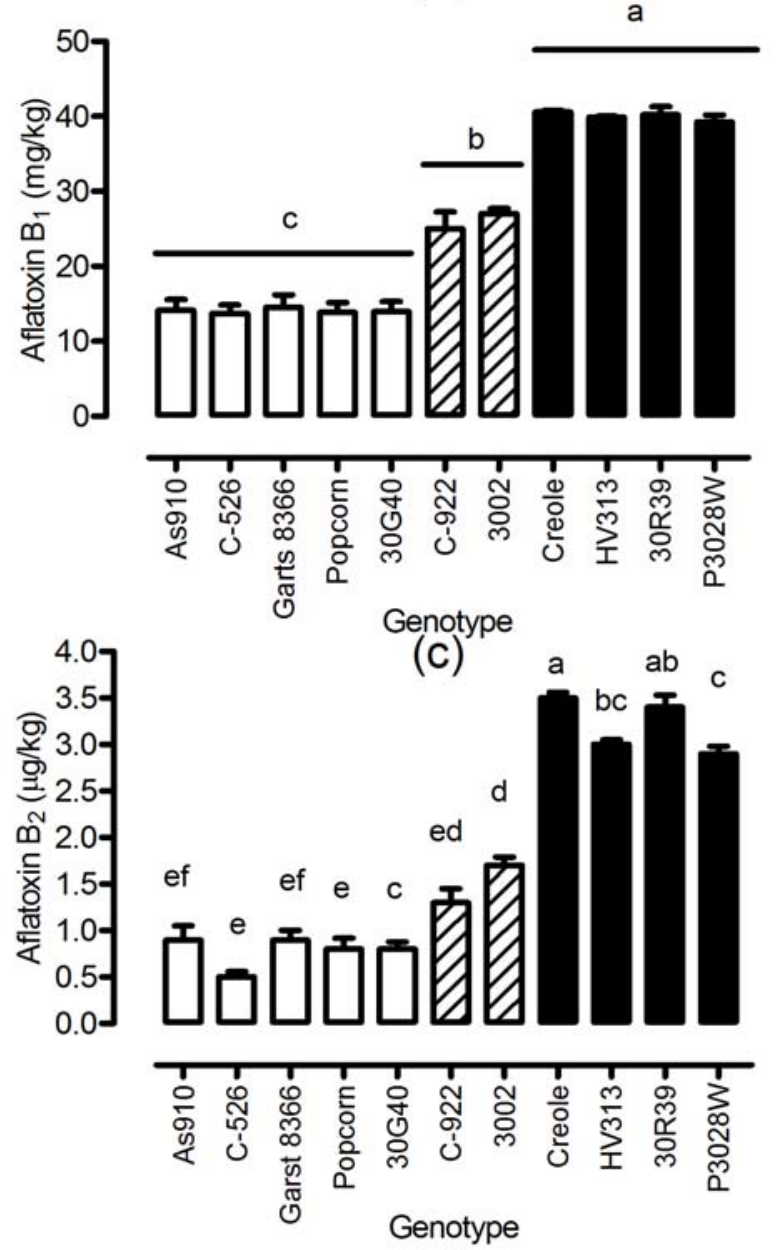

(e)

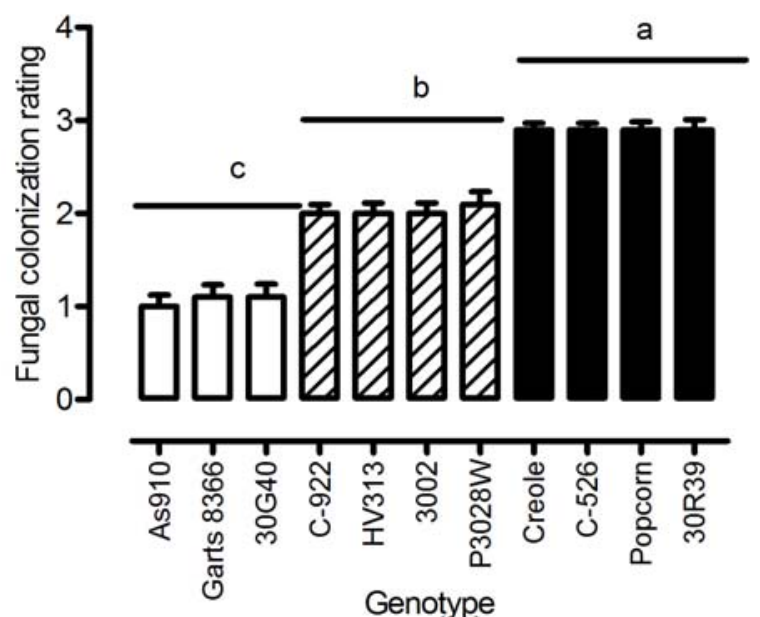

(b)

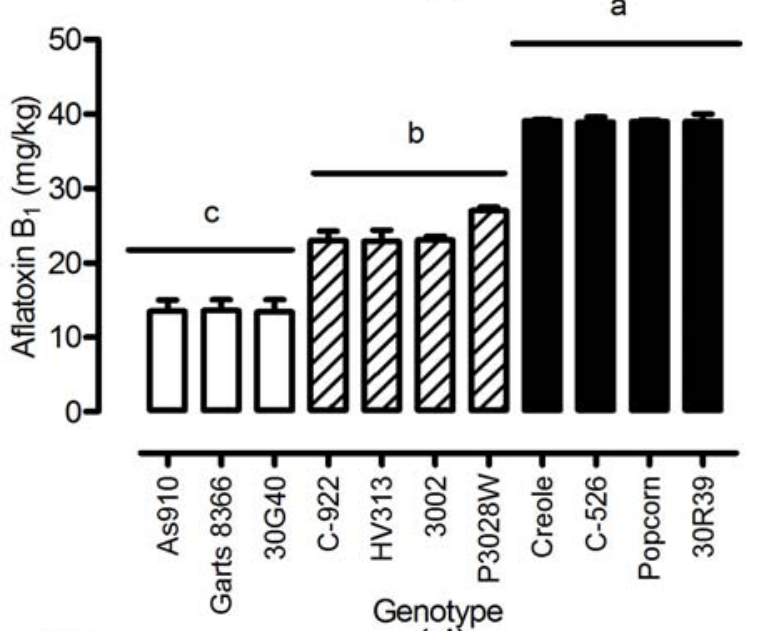

(d)

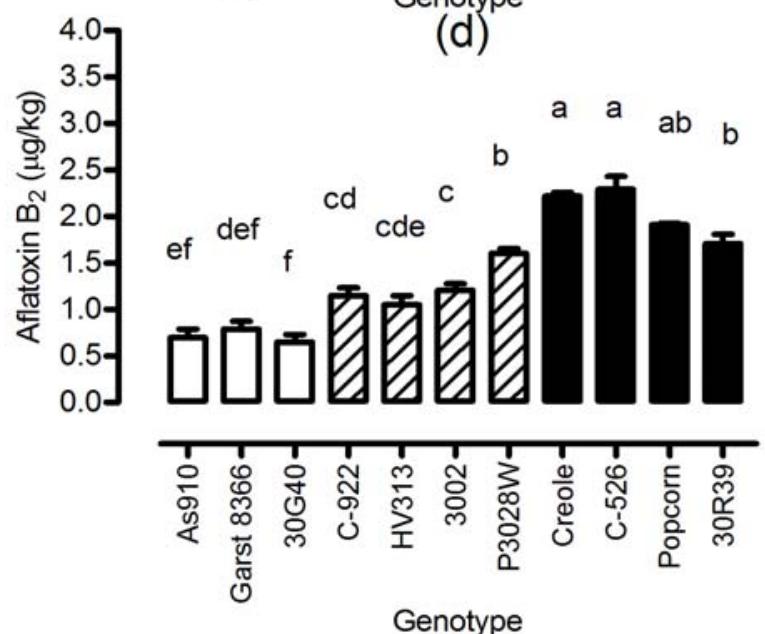

(f)

Group:

Resistant

C2 Medium

Susceptible

Fig. 3 Resistance of 11 genotypes of immature maize grains to fungal colonization. (a) and (b): fungal colonization, expressed as the invasion of grain surface at level $0,1,2$ or 3; (c)-(f): aflatoxins production $\left(B_{1}\right.$ and $\left.B_{2}\right)$ from two Aspergillus flavus strains. Literals indicate significant differences, studentized Tukey test $(P<0.05 ; n=20)$. 
and 30G40; Fig. 3d). Those genotypes showed the lowest concentrations $(P<0.01)$ of $\mathrm{AFB}_{1}$ produced by both A. flavus strains.

Genotypes resistant to $\mathrm{AFB}_{2}$ produced by the Cuautitlan strain were C-526, Popcorn, 30G40, Garst 8366 and $A s 910$ (Fig. 3e). For the Tamaulipas strain, resistant genotypes to $\mathrm{AFB}_{2}$ accumulation were $30 \mathrm{G} 40$, As 910 and Garst 8366 (Fig. 3f). $\mathrm{AFB}_{2}$ accumulation in resistant genotypes was significantly lower $(P<0.01)$ compared to control groups of each genotype for both strains.

$\mathrm{FC}$ and $\mathrm{AF}$ accumulation $\mathrm{B}_{1}$ and $\mathrm{B}_{2}$ were significantly related $(P<0.01)$, probably due to the interaction between maize genotype and fungal strains. When AF production was compared in each strain, a positive correlation was observed (Fig. 4) between colonization by A. flavus strains and the production of $\mathrm{AFB}_{1}$ and $\mathrm{AFB}_{2}(P<0.01$, with Pearson coefficients of $94 \%$ to $99 \%$ ). Regression analysis showed a significant influence $(P<0.01)$ of $\mathrm{FC}$ on $\mathrm{AFB}_{1}$ and $\mathrm{AFB}_{2}$ production (Figs. $4 \mathrm{a}$ and $4 \mathrm{~b}$, respectively); the determination coefficient for the Cuautitlan strain reached values of $R^{2}=99.5 \%$ and $93.2 \%$, respectively. Whereas for the Tamaulipas strain values were $R^{2}=$ $87.2 \%$ and $73.2 \%$, respectively. Concerning grain colonization, the Tamaulipas strain was more aggressive than the Cuautitlan strain $(P<0.01)$, however the latter strain had the highest production levels of $\mathrm{AFB}_{1}$ and $\mathrm{AFB}_{2}$ from the 11 maize genotypes.

This study evaluated the resistance of 11 maize genotypes to AF accumulation, and the AF was produced by two Mexican strains of Aspergillus flavus under controlled conditions of temperature, humidity and infective dose. The results showed that maize genotype was associated with the level of colonization of each strain, which had significant differences in their ability to infect grains. Moreover, FC determined the accumulation of $\mathrm{AFB}_{1}$ and $\mathrm{AFB}_{2}$. These findings are reported for the first time using indigenous toxicogenic strains and maize genotypes widely used in Mexico. This information is highly relevant to agriculture and
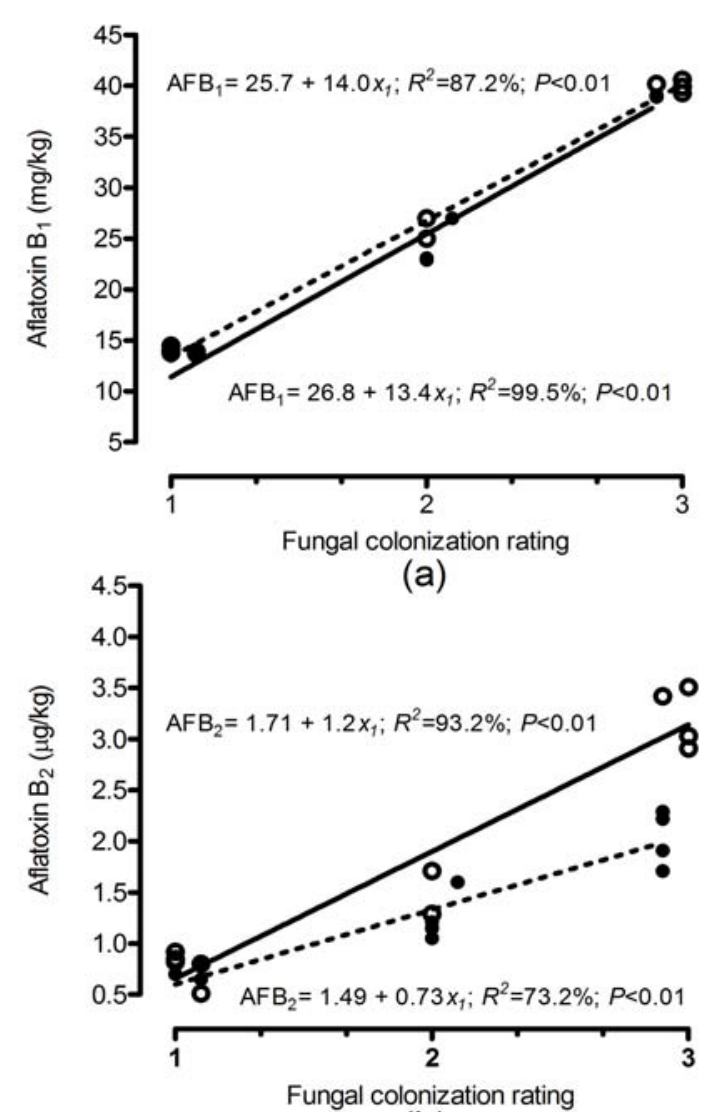

(b)

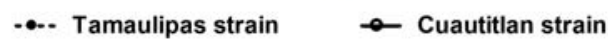

Fig. 4 Regression analysis between $\mathrm{AFB}_{1}$ (a) and $\mathrm{AFB}_{2}$ (b) production and fungal colonization rating $\left(x_{1}\right), R^{2}=$ coefficient of determination.

the food industry, since it might reduce the risk of human exposure through the production and selection of maize genotypes resistant to colonization of $A$. flavus.

This would be a complementary alternative to other strategies that have been described to diminish the impact of food contamination, such as the use of competitive non-toxicogenic strains [43], biological control agents (bacteria, yeasts) [44], insect control [45, 46], chemical and physical grain treatments [47] and the addition of sequestrants in animal diets [48, 49].

This study evaluated the resistance of 11 maize grain genotypes to $\mathrm{FC}$, as well as $\mathrm{AF}$ accumulation from two toxicogenic A. flavus strains during 14 days. There were significant differences in $\mathrm{AF}$ accumulation, which was related with $\mathrm{FC}$ on the different maize 
genotypes. Ankala et al. [29] and Kelley et al. [50] demonstrated that the non-commercial maize line (Mp313E, Mp04:86) is resistant to A. flavus infection, and suggested an association with the defense mechanisms of the plant [9]. Chen et al. [51] suggested that the main factors for resistance are the synthesis of antifungal proteins and the presence of physical barriers, such as pericarp thickness. In this study, in agreement with the Chen report, the Popcorn genotype characterized by its thick pericarp, showed to be resistant to infection. Other studies in endogamic maize hybrids have shown that if the pericarp is intact, the possibility of invasion by A. flavus and other pathogen agents is reduced [30]. In addition, Barros-Rios et al. [28] evaluated the structure and composition of the cell wall in maize grains and concluded that its thickness is a barrier which prevents grain damage caused by phytopathogens.

Maize genotypes As910, Garst 8366 and $30 G 40$ do not present a hard pericarp, which suggests that their defense mechanisms against fungi might be related to the synthesis of antifungal compounds. It is known that control of phenotypic traits, such as maize resistance to fungal colonization and $\mathrm{AF}$ accumulation, involves gene expression [52]. Gene expression related to maize resistance to infection has been associated to environmental factors, such as scarcity of water [53-55]. Ehrlich et al. [56] have shown that gene hypC, involved in AF synthesis is activated under conditions that inhibit fungal growth. Since this study was performed under controlled conditions of fungal growth, it is suggested that intrinsic genetic factors associated to $\mathrm{FC}$ resistance and $\mathrm{AF}$ accumulation were decisive for the results. The data show that fungi ability to produce $\mathrm{AF}\left(\mathrm{B}_{1}\right.$ and $\left.\mathrm{B}_{2}\right)$ was determined by the $A$. flavus capacity to colonize maize grains. The correlation between $\mathrm{FC}$ and $\mathrm{AF}$ accumulation was analyzed during a 14-day period, and a positive association between these two variables was found. Therefore, maize genotypes resistant to colonization (As910, Garts 8366 and 30G40) also showed resistance to $\mathrm{AF}$ accumulation $\left(\mathrm{B}_{1}\right.$ and $\left.\mathrm{B}_{2}\right)$; meanwhile genotypes less resistant to colonization (30R39, P3028W, HV313 and Creole) also showed the highest levels of $\mathrm{AF}$ accumulation. These results are in agreement with reports which stated that maize lines with high colonization levels also presented a significant accumulation of AF [27, 57]. Furthermore, it has been shown that mycotoxins, as secondary metabolites, are produced once the initial vegetative growth phase of the fungus has been completed after the conidia contacting the grain and are able to germinate [29, 58-60]. So if there is a delay in colonization, it also causes a delay in the buildup of AF in grains.

Significant differences were observed among the 11 maize genotypes concerning colonization capacity and AF production caused by the indigenous strains of $A$. flavus, and suggests that the invasiveness and pathogenicity of those strains are genetically determined. These results are in agreement with those who reported that difference in morphology and physiology of $A$. flavus strains is related to their ability to invade, use its resources and contaminat the grain [9, 61, 62]. These differences would explain the differential incidence of $\mathrm{AF}$ levels restricted to agricultural harvests produced in specific seasons and areas as well as associated to the presence of toxicogenic strains that interact with genotypic susceptibility and the environmental conditions prevailing in each agricultural cycle $[30,63,64]$.

\section{Conclusions}

In this study, it showed that maize genotype is associated with the colonization level of maize grain by Aspergillus flavus. Significant differences are also observed in the capacity of the fungal strains to infect maize grains, as well as in genotype-strain interaction. In turn, colonization levels determined the concentration of accumulated AF. Only some maize genotypes (Garst 8366, Popcorn, As910 and C-526) showed resistance to fungal growth and consequent $\mathrm{AF}$ accumulation. These data suggest that physical barriers 
and the presence of antifungal compounds in some maize genotypes confer resistance to fungal invasion. Therefore, production and selection of maize genotypes resistant to toxicogenic strains of Aspergillus flavus would reduce the risk of human exposure to contaminated food.

\section{Acknowledgments}

The authors thank Universidad Autónoma de Aguascalientes (project PIP/SA 12-3), and Consejo Nacional de Ciencia y Tecnología (Fellowship $386650 / 256513$ ) for its financial support. The authors also thank UNAM researcher Ernesto Moreno Martínez, UAA professors Roberto Rico, José de Jesús Luna and José Luis Moreno as well as Martin Ortiz Lopez for the help given, so that this study could be published.

\section{References}

[1] G.A. Payne, Aflatoxin in maize, Crit. Rev. Plant. Sci. 10 (1992) 423-440.

[2] Food and Agriculture Organization of the United Nations (FAO), Foodborne Diseases and Their Socioeconomic Impact, Technical Report on Agricultural and Food Engineering, Roma, France, 2009. (in Spanish)

[3] L.A. Rodriguez-del-Bosque, Impact of agronomic factors on aflatoxin contamination in preharvest field corn in Northeastern Mexico, Plant Dis. 80 (1996) 988-993.

[4] C.M. Bucio-Villalobos, D. Guzmán-de-Peña, J.J. Peña-Cabriales, Aflatoxin synthesis in corn fields in Guanajuato, Mexico, Rev. Iberoam. Micol. 18 (2001) 83-87.

[5] G.L. Windham, W.P. Williams, Evaluation of corn inbreds and advanced breeding lines for resistance to aflatoxin contamination in the field, Plant Dis. 82 (2002) 232-234.

[6] S. Bhatnagar, F.J. Betrán, L.W. Rooney, Combining abilities of quality protein maize inbreds, Crop Sci. 44 (2004) 1997-2005.

[7] S.K. Jand, P. Kaur, N.S. Sharma, Mycoses and mycotoxicosis in poultry: A review, Indian J. Anim. Sci. 75 (2005) 465-476.

[8] P. Vardon, C. McLaughlin, C. Nardinelli, Potential economic costs of mycotoxins in the United States, in: Mycotoxins: Risks in Plant, Animal and Human Systems, CAST, Iowa, United States, 2003, pp. 136-142.

[9] DD. Deng, S. Jiang, Y. Wang, Y. Bian, J. Chen, B. Jia, Genetic analysis of the resistance to Aspergillus flavus infection in maize (Zea mays L.), Agric. Sci. China 8 (2009) 761-765.

[10] J.W. Cary, K. Rajasekaran, R.L. Brown, M. Luo, Z.Y. Chen, D. Bhatnagar, Developing resistance to aflatoxin in maize and cottonseed, Toxins 3 (2011) 678-696.

[11] E. Torres, K. Acuña, L. Naccha, J.P. Castellon, Quantification of aflatoxins in corn distributed in the city of Monterrey, Mexico, Food Add. Contam. 12 (1995) 383-386.

[12] J.A. Méndez-Albores, G. Arámbula-Villa, R.E. Preciado-Ortíz, E. Moreno-Martínez, Aflatoxins in pozol, a nixtamalized, maize-based food, Int. J. Food Microbiol. 94 (2004) 211-215.

[13] S. García, N. Heredia, Mycotoxins in Mexico: Epidemiology, management, and control strategies, Mycopathologia 162 (2006) 255-264.

[14] Information Statement of the Institute of Food Science \& Technology (IFST), Mycotoxins [Online], http://www.ifst.org.

[15] G.N. Montes, C.A. Reyes, R.N. Montes, M.A. Cantu, Incidence of potentially toxigenic fungi in maize (Zea mays L.) grain used as food and animal feed, CyTA J. Food 7 (2009) 119-125.

[16] Food and Fisheries Information Service (SIAP) [Online], http://www.siap.gob.mx. (in Spanish)

[17] International Agency for Research on Cancer (IARC), Monograph on the Evaluation of Carcinogenic Risk to Human, IARC Press, Lyon, France, 2002, Vol. 82, pp. 223-249.

[18] W.L. Bryden, Mycotoxin contamination of the feed supply chain: Implications for animal productivity and feed security, Anim. Feed Sci. Tech. 173 (2012) 134-158.

[19] W.B. Henry, Maize aflatoxin accumulation segregates with early maturing selections from an S2 breeding cross population, Toxins 5 (2013) 162-172.

[20] H.K. Abbas, M.A. Weaver, B.W. Horn, I. Carbone, J.T. Monacell, W.T. Shier, Selection of Aspergillus flavus isolates for biological control of aflatoxins in corn, Toxin Rev. 30 (2011) 59-70.

[21] X. Ni, J.P. Wilson, G.D. Buntin, B. Guo, M.D. Krakowsky, R.D. Lee, et al., Spatial patterns of aflatoxin levels in relation to ear-feeding insect damage in pre-harvest corn, Toxins 3 (2011) 920-931.

[22] X. Ni, J.P. Wilson, M.D. Toews, G.D. Buntin, R.D. Lee, X. $\mathrm{Li}$, et al., Evaluation of spatial and temporal patterns of insect damage and aflatoxin level in the pre-harvest corn fields to improve management tactics, Insect Sci., Sep. 3, 2012. DOI: 10.1111/j.1744-7917.2012.01531.x.

[23] Food and Agriculture Organization of the United Nations (FAO), Safety evaluation of certain mycotoxins in food, in: 56th Meeting of the Joint FAO/WHO Expert Committee on Food Additives, FAO Food and Nutrition Paper No. 74, 


\section{Association between Aspergillus flavus Colonization and Aflatoxins Production in Immature Grains of Maize Genotypes}

Rome, France, 2001.

[24] W.B. Henry, G.L. Windham, M.H. Blanco, Evaluation of maize germplasm for resistance to aflatoxin accumulation, Agronomy 2 (2012) 28-39.

[25] B.W. Horn, Ecology and population biology of aflatoxigenic fungi in soil, J. Toxicol. Toxin Rev. 22 (2003) 351-379.

[26] Z.Y. Chen, R.L. Brown, K.E. Damann, T.E. Cleveland, Identification of maize kernel endosperm proteins associated with resistance to aflatoxin contamination by Aspergillus flavus, Phytopathology 97 (2007) 1094-1103.

[27] R.L. Brown, Z.Y. Chen, M. Warburton, M. Luo, A. Menkir, A. Fakhoury, et al., Discovery and characterization of proteins associated with aflatoxin-resistance: Evaluating their potential as breeding markers, Toxins 2 (2010) 919-933.

[28] J. Barros-Rios, R.A. Malvar, H.J.G. Jung, R. Santiago, Cell wall composition as a maize defense mechanism against corn borers, Phytochemistry 72 (2011) 365-371.

[29] A. Ankala, B.K. Bolla, R. Shivaji, W.P. Williams, J.R. Wilkinson, Comparative analysis of the performance of Aspergillus flavus on resistant and susceptible maize genotypes during infection, Fungal Ecol. 4 (2011) 32-41.

[30] R.D. Walker, D.G. White, Inheritance of resistance to Aspergillus ear rot and aflatoxin production of corn from CI2, Plant Dis. 85 (2001) 322-327.

[31] F.J. Betrán, T. Isakeit, G. Odvody, Aflatoxin accumulation of white and yellow maize inbreds in diallel crosses, Crop Sci. 42 (2002) 1894-1901.

[32] H.D. Gardner, W.P. Williams, G.L. Windham, Diallel analysis of aflatoxin accumulation in maize, Field Crop Res. 102 (2007) 60-63.

[33] W.P. Williams, S. Ozkan, A. Ankala, G.L. Windham, Ear rot, aflatoxin accumulation and fungal biomass in maize after inoculation with Aspergillus flavus, Field Crop Res. 120 (2011) 196-200.

[34] A. Martínez-de-Anda, A.G. Valdivia, F. Jaramillo-Juárez, J.L. Reyes, R. Ortiz, T. Quezada, et al., Effects of aflatoxin chronic intoxication in renal function of laying hens, Poultry Sci. 89 (2010) 1622-1628.

[35] R. Gaytán-Bautista, M.I. Martínez-Gómez, N. Mayek-Pérez, Grain and forage yield in maize hybrids and their advanced $\mathrm{F}_{2}$ generation, Agr. Tec. Mex. 35 (2009) 295-304.

[36] H.G. Núñez, G.E.F. Contreras, C.R. Faz, Important agronomic and chemicals characteristics in high energy hybrid forage corns, Tec. Pecu. Mex. 41 (2003) 37-48.

[37] J.M. Wells, J.A. Payne, Toxigenic Aspergillus and Penicillium isolates from weevil-damaged chestnuts, Appl. Microbiol. 30 (1975) 536-540.

[38] G.L. Windham, W.P. Williams, P.M. Buckley, H.K. Abbas, Inoculation techniques used to quantify aflatoxin resistance in corn, J. Toxicol. Toxin Rev. 22 (2003) 313-325.

[39] D. Shoemaker, M. Torchia, Laboratory safety, appendix B, in: Official Methods of Analysis of the Association of Official Analytical Chemist, Virginia, United States, 1995, Vol. 49, pp. 1-7.

[40] Aflatoxin Handbook, United States Department of Agriculture (USDA), Washington, United States, 2002, Vol. 2, pp. 1-9.

[41] B.Z. Guo, J.S. Russin, R.L. Brown, T.E. Cleveland, N.W. Widstrom, Resistance to aflatoxin contamination in corn as influenced by relative humidity and kernel germination, J. Food Prot. 59 (1995) 276-281.

[42] P.M. Scott, Natural toxins, AOAC. 49 (1995) 1-30.

[43] D. Bhatnagar, J.W. Cary, K. Ehrlich, J. Yu, T.E. Cleveland, Understanding the genetics of regulation of aflatoxin production and Aspergillus flavus development, Mycopathologia 162 (2006) 155-166.

[44] M.G. Etcheverry, A. Scandolara, A. Nesci, M.S. Vilas-Boas-Ribeiro, P. Pereira, P. Battilani, Biological interactions to select biocontrol agents against toxigenic strains of Aspergillus flavus and Fusarium verticillioides from maize, Mycopathologia 167 (2009) 287-295.

[45] T.E. Cleveland, P.F. Dowd, A.E. Desjardins, D. Bhatnagar, P.J. Cotty, United States Department of Agriculture-Agricultural Research Service research on pre-harvest prevention of mycotoxins and mycotoxigenic fungi in US crops, Pest Manag. Sci. 59 (2003) 629-642.

[46] H.K. Abbas, J.R. Wilkinson, R.M. Zablotowicz, C. Accinelli, C.A. Abel, H.A. Bruns, et al., Ecology of Aspergillus flavus, regulation of aflatoxin production, and management strategies to reduce aflatoxin contamination of corn, Toxin Rev. 28 (2009) 142-153.

[47] A. Yiannikouris, J.P. Jouany, Mycotoxins in feeds and their fate in animals: A review, Anim. Res. 51 (2002) 81-99.

[48] D.E. Diaz, W.M. Hagler Jr., B.A. Hopkins, L.W. Whitlow, Aflatoxin binders I: In vitro binding assay for aflatoxin $\mathrm{B}_{1}$ by several potential sequestering agents, Mycopathologia 156 (2002) 223-226.

[49] D.E. Diaz, W.M. Hagler Jr., J.T. Blackwelder, J.A. Eve, B.A. Hopkins, K.L. Anderson, et al., Aflatoxin binders II: Reduction of aflatoxin $\mathrm{M}_{1}$ in milk by sequestering agents of cows consuming aflatoxin in feed, Mycopathologia 157 (2004) 233-241.

[50] R.Y. Kelley, W.P. Williams, J.E. Mylroie, D.L. Boykin, J.W. Harper, G.L. Windham, et al., Identification of maize genes associated with host plant resistance or susceptibility to Aspergillus flavus infection and aflatoxin accumulation, PLOS ONE, 2012. DOI: 10.1371/journal.pone.0036892.

[51] Z.Y. Chen, R.L. Brown, T.E. Cleveland, Evidence for an association in corn between stress tolerance and resistance 
to Aspergillus flavus infection and aflatoxin contamination, Afr. J. Biotechnol. 3 (2004) 693-699.

[52] A. Menkir, R.L. Brown, R. Bandyopadhyay, Z. Chen, T.E. Cleveland, A USA-Africa collaborative strategy for identifying, characterizing and developing maize germplasm with resistance to aflatoxin contamination, Mycopathologia 162 (2006) 225-232.

[53] C. Paul, G. Naidoo, A. Forbes, V. Mikkilineni, D. White, T. Rocheford, Quantitative trait loci for low aflatoxin production in two related maize populations, Theor. Appl. Genet. 107 (2003) 263-270.

[54] Z. Wang, J. Liu, D. Lee, B. Scully, B. Guo, Postharvest Aspergillus flavus colonization in responding to preharvest field condition of drought stress and oligo-macroarray profiling of developing corn kernel gene expression under drought stress, Phytopathology 98 (2008) S166.

[55] M.L. Warburton, T.D. Brooks, G.L. Windham, W.P. Williams, Identification of novel QTL contributing resistance to aflatoxin accumulation in maize, Mol. Breeding 27 (2011) 491-499.

[56] K.C. Ehrlich, P. Li, L. Scharfenstein, P.K. Chang, HypC, the anthrone oxidase involved in aflatoxin biosynthesis, Appl. Environ. Microb. 76 (2010) 3374-3377.

[57] Z.Y. Chen, R.L. Brown, K.E. Damann, T.E. Cleveland, PR10 expression in maize and its effect on host resistance against Aspergillus flavus infection and aflatoxin production, Mol. Plant. Pathol. 11 (2010) 69-81.
[58] J. Sekiguchi, G.M. Gaucher, Conidiogenesis and secondary metabolism in Penicillium urticae, Appl. Environ. Microb. 33 (1977) 147-158.

[59] A.M. Calvo, R.A. Wilson, J.W. Bok, N.P. Keller, Relationship between secondary metabolism and fungal development, Microbiol. Mol. Biol. R. 66 (2002) 447-459.

[60] K.C. Ehrlich, Q. Wei, R.L. Brown, D. Bhatnagar, Inverse correlation of ability to produce aflatoxin and Aspergillus colonization of corn seed, Food Nutr. Sci. 2 (2011) 486-489.

[61] M. Razzaghi-Abyaneh, M. Shams-Ghahfarokhi, A. Allameh, A. Kazeroon-Shiri, S. Ranjbar-Bahadori, H. Mirzahoseini, et al., A survey on distribution of Aspergillus section Flavi in corn field soils in Iran: Population patterns based on aflatoxins, cyclopiazonic acid and sclerotia production, Mycopathologia 161 (2006) 183-192.

[62] J. Gao, Z. Liu, J. Yu, Identification of Aspergillus section Flavi in maize in Northeastern China, Mycopathologia 164 (2007) 91-95.

[63] H.L. Mehl, P.J. Cotty, Variation in competitive ability among isolates of Aspergillus flavus from different vegetative compatibility groups during maize infection, Phytopathology 100 (2010) 150-159.

[64] C. Probst, F. Schulthess, P.J. Cotty, Impact of Aspergillus section Flavi community structure on the development of lethal levels of aflatoxins in Kenyan maize (Zea mays), J. Appl. Microbiol. 108 (2010) 600-610. 